\title{
Characterization, chemical modifications and in vitro anticoagulant properties of an exopolysaccharide produced by Alteromonas infernus
}

\author{
Sylvia Colliec Jouault a,*, Lionel Chevolot a, Dominique Helley ${ }^{\mathrm{b}}$, Jacqueline Ratiskol a, \\ Andrée Bros ${ }^{b}$, Corinne Sinquin ${ }^{a}$, Olivier Roger ${ }^{a}$, Anne-Marie Fischer ${ }^{b}$ \\ a URM2, IFREMER/CNRS (UMR 7540, CNRS/Université Paris 13), Laboratoire de Biochimie et Molécules Marines, Département Valorisation des \\ Produits, BP 21105, 44311 Nantes Cedex 3, France \\ b Laboratoire d'Hématologie, CHU Necker-Enfants Malades (Université Paris VIINSERM U 428), Paris, France
}

Received 7 March 2001; received in revised form 2 July 2001; accepted 12 July 2001

\begin{abstract}
A new low-molecular-weight 'heparin-like' component was obtained from an exopolysaccharide produced by a mesophilic strain found in deep-sea hydrothermal vents. Data concerning the structure of the native high-molecular-weight exopolysaccharide $\left(10^{6} \mathrm{~g} / \mathrm{mol}, 10 \% \mathrm{sulfate}\right.$ content) are reported for the first time. Two depolymerization processes were used to obtain low-molecular-weight $\left(24-35 \times 10^{3} \mathrm{~g} / \mathrm{mol}\right)$ oversulfated fractions (sulfate content 20 or 40 ). Nuclear magnetic resonance studies indicated that after sulfation (40\%), the low-molecularweight fraction obtained by free radical depolymerization was less sulfated in the 6- $O$-position than the fraction depolymerized by acid hydrolysis. The free radical depolymerized product also had sulfated residues in the 4-O-position and disulfated ones in the 2,3-O-positions. Moreover, the compounds generated by the free radical process were more homogeneous with respect to molecular mass. Also for the first time, the anticoagulant activity of the low-molecular-weight exopolysaccharide fractions is reported. When the fractions obtained after sulfation and depolymerization were compared with heparins, anticoagulant activity was detected in oversulfated fractions, but not in native exopolysaccharide. The free radical depolymerized fraction inhibited thrombin generation in both contact-activated and thromboplastinactivated plasma, showing a prolonged lag phase only in the contact-activated assay. Affinity co-electrophoresis studies suggested that a single population of polysaccharide chains binds to antithrombin and that only a subpopulation strongly interacts with heparin cofactor II. (C) 2001 Published by Elsevier Science B.V.
\end{abstract}

Keywords: Affinity co-electrophoresis; Anticoagulant activity; Depolymerization; Heparin-like; Serpin; Sulfated polysaccharide; Sulfation

\section{Introduction}

A broad series of polysaccharides has emerged as an important class of bioactive products [1] that occur naturally in a great variety of animals, plants and microorganisms. Marine microorganisms offer a rich source of polysaccharides with novel structures. Since 1994, new bacteria have been searched for near deep-sea hydrothermal vents characterized by extreme pressure and temperature condi-

Abbreviations: EPS, exopolysaccharide; LMW, low molecular weight; H-EPS, hydrolyzed native EPS; H-LMW EPS, low-molecular-weight sulfated exopolysaccharides obtained by acid hydrolysis; R-LMW EPS, lowmolecular-weight sulfated exopolysaccharides obtained by radical depolymerization; HPSEC, high-performance size-exclusion chromatography; APTT, activated partial thromboplastin time; TT, thrombin clotting time; PPP, platelet-poor plasma; AT, antithrombin; HCII, heparin cofactor II; ACE, affinity co-electrophoresis

* Corresponding author. Fax: +33-2-40-37-40-93.

E-mail address: sylvia.colliec.jouault@ifremer.fr (S. Colliec Jouault). tions and high concentrations of toxic elements [2,3]. Interest in mass culture of microorganisms from the marine environment has increased considerably, representing an innovative approach to the biotechnological use of under-exploited resources [4]. Exopolysaccharide (EPS)producing microorganisms occur very widely in nature in different types of habitat [5], and some thermophilic and mesophilic EPS-producing strains have been isolated from deep-sea hydrothermal vents $[2,6]$. Some bacteria (e.g. Alteromonas macleodii subsp. fijiensis and Vibrio diabolicus) found in these conditions have produced extracellular polymers with original structures when grown in an aerobic carbohydrate-based medium [7,8]. Alteromonas infernus, a new species of bacterium isolated quite recently [9] and classified as a non-pathogenic microorganism by the Institut Pasteur, secretes a water-soluble acidic heteropolysaccharide consisting of glucose, galactose, glucuronic and galacturonic acids $(1: 1: 0.7: 0.4)$. The composition of this high-molecular-weight polysaccharide $\left(10^{6} \mathrm{~g} / \mathrm{mol}\right)$ differs 
in monosaccharide content and/or ratio and sulfate content $(10 \%)$ from other EPS isolated from deep-sea hydrothermal bacteria and from polysaccharides of other origins. In a preliminary study, highly sulfated lowmolecular-weight (LMW) EPS fractions were obtained after combined sulfation and acidic depolymerization, without altering the osidic composition of this acidic polymer [10]. However, no data concerning the structure and biological activity of these fractions were currently available until now.

The preparation of therapeutic products from nonmammalian sources would avoid the risk of contamination with pathogenic agents potentially present in mammalian tissues [11-15]. In this respect, sulfated polysaccharides constitute a complex group of macromolecules known to possess a wide range of important biological properties. Heparin of porcine origin, a heterogeneous sulfated polysaccharide from the growing family of glycosaminoglycans, is widely used as a therapeutic anticoagulant and antithrombotic agent [16]. It is now clearly established that the sulfate groups in heparin play a critical role in its antithrombotic activity [17]. However, as heparin has pharmacokinetic and biophysical limitations, attempts have been made to develop new anticoagulant and antithrombotic drugs $[18,19]$. Various studies have concerned new sulfated polysaccharides that show anticoagulant/antithrombotic properties and target specific steps in thrombogenesis. These polysaccharides (e.g. fucoidan, dermatan sulfate and sulfated dextran derivatives) show no structural homology with heparin, except high sulfate content [14, $15,20-25]$.

The native EPS secreted by $A$. infernus is without anticoagulant activity and was chemically modified to induce it. This study provides the first data on the structure of the native EPS and the fractions obtained after sulfation and depolymerization performed by acid hydrolysis or radical depolymerization. The anticoagulant activities of oversulfated LMW EPS fractions (containing uronic acid and sulfate contents comparable to those of heparin) were compared with those of heparin. Thrombin generation tests were performed in the presence of the most homogeneous fraction to study the mechanism of anticoagulant activity, and the interaction of this fraction with serpins was analyzed by affinity co-electrophoresis (ACE).

\section{Materials and methods}

\subsection{Materials}

LMW heparin (Dalteparin, Fragmin; 160 anti-Xa IU/ mg) was obtained from Kabi Pharmacia (St. Quentin, France). Purified human thrombin (2910 NIH units/mg), unfractionated heparin from porcine mucosa used in ACE experiments $(25-35 \mathrm{kDa}$ in low-angle laser measurements by the manufacturer, and $29 \mathrm{kDa}$ as determined in our laboratory (see Section 2.6)), dextran sulfate (8 kDa), azure A, toluidine blue and sodium Mopso were from Sigma (St. Louis, MO, USA). Unfractionated heparin (batch $\mathrm{H} 108 ; 173 \mathrm{IU} / \mathrm{mg}$ ) for anticoagulant assays was from Sanofi Winthrop (Paris, France). Reptilase-STH50 and purified human heparin cofactor II (1 PEU/100 $\mu \mathrm{g})$ were from Diagnostica Stago (Asnières, France), APTT from Organon Technika (Fresnes, France), purified human antithrombin from Chromogenix (5 units/mg), chromogenic substrate S-2238 from Biogenic (Maurin, France), Thromborel-S (human thromboplastin without Polybrene) from Behring (Marburg, Germany), and Chelex 100 resin and low-melt preparative grade agarose were from BioRad (Ivry sur Seine, France). APTT-ES reagent (ellagic acid+cephalin) used for the thrombin generation test was kindly provided by Helena (St. Leu, France). The Standard Filtron Cassette System was supplied by Pall Filtron (Northborough, MA, USA). Cetavlon (cetyltrimethylammonium bromide) was from Merck (Darmstadt, Germany), and gel bond films were from Pharmacia (Uppsala, Sweden). The affinity co-electrophoresis system was from Owl Scientific (Woburn, MA, USA).

\subsection{Production, purification and characterization of native exopolysaccharide}

The isolation procedure and characteristics of the GY785 strain were previously reported [9]. EPS was produced and purified as previously described [10], and monosaccharide content was determined after methanolysis by gas chromatography [8]. Methylation analyses were performed using a modification of the Hakomori procedure [26]. Hydroxyl groups were methylated by methyl iodide in DMSO using lithium dimethylsulfinyl as anion. Methyl esters of uronic acids were reduced by lithium triethylborodeuteride, as previously described [27]. Methylated EPS was then hydrolyzed with $2 \mathrm{M}$ trifluoroacetic acid for $2 \mathrm{~h}$ at $120^{\circ} \mathrm{C}$. The derivatives were reduced by $\mathrm{NaBD}_{4}$ and acetylated prior to analysis by gas chromatography-mass spectrometry (GC/MS) [8]. The main peaks were numbered from 1 to 11 . As peak response (total ionic current) depends on the structure, such analyses are more qualitative than quantitative.

\subsection{Preparation of partially hydrolyzed exopolysaccharide (H-EPS)}

Crude EPS was dissolved in $0.5 \mathrm{M} \mathrm{H}_{2} \mathrm{SO}_{4}$ at $5 \mathrm{mg} / \mathrm{ml}$ and heated at $60^{\circ} \mathrm{C}$ for $90 \mathrm{~min}$. The preparation was then neutralized with a solution of $1 \mathrm{M} \mathrm{NaOH}$, ultrafiltrated (1000 Da cutoff membrane) to eliminate salts and small oligosaccharides, and finally freeze-dried. The molecular weight of the H-EPS was $10000 \mathrm{~g} / \mathrm{mol}$ and its polydispersity 1.9 (determined as described in Section 2.6). Methylation analysis was performed as described above. 


\subsection{Proton nuclear magnetic resonance (NMR) spectros- copy}

1D ${ }^{1} \mathrm{H}$ NMR spectra were recorded for hydrolyzed native EPS (H-EPS) and modified fractions (H- $(20 \%$ sulfate); $\mathrm{H}-(40 \%$ sulfate $)$ and $\mathrm{R}-(40 \%$ sulfate $))$ on a Bruker DRX-500 spectrometer, equipped with an indirect $5 \mathrm{~mm}$ ${ }^{1} \mathrm{H}\{\mathrm{BB}\}$ gradient probe head, at probe temperatures of $298 \mathrm{~K}$ or $328 \mathrm{~K}$. Prior to analysis, samples were exchanged twice in $\mathrm{D}_{2} \mathrm{O}$. Chemical shifts are expressed in ppm with reference to an external standard (trimethylsilylpropionic acid). No suppression of the HOD signal was performed. Detailed sample preparation and recording conditions were published previously [28].

\subsection{Sulfation and depolymerization of exopolysaccharide}

EPS was chemically oversulfated according to a previously described direct sulfation procedure [29]. Following sulfation, two oversulfated EPSs with $20 \%$ and $40 \%$ sulfate groups $(\mathrm{w} / \mathrm{w})$ were prepared, depending on experimental conditions. Both oversulfated EPSs were depolymerized by acid hydrolysis (H-fractions), and two LMW EPS fractions were isolated following fractionation by gel-filtration chromatography, yielding $\mathrm{H}-(20 \%$ sulfate $)$ and $\mathrm{H}-(40 \%$ sulfate) fractions respectively [10]. The $40 \%$ sulfated EPS was also depolymerized by a radical (R-fraction) process using a modification of the procedure of Nardella et al. [30]. Four hundred milligrams of $40 \%$ sulfated EPS were dissolved in water $(95 \mathrm{ml})$ in a reaction vessel, and $5 \mathrm{ml}$ of $3 \times 10^{-3} \mathrm{M}$ cupric acetate monohydrate were added. The temperature was kept at $60^{\circ} \mathrm{C}$. A $0.07 \%$ (w/w) hydrogen peroxide solution was then added at a flow rate of $60 \mathrm{ml} / \mathrm{h}$. The reaction was stopped after 2.5 $h$, and the contaminating copper ions were removed from the product by chromatography on Chelex 100 resin (in $\mathrm{Na}^{+}$form), with water as eluent. The solution was concentrated, desalinated by ultrafiltration with a $1000 \mathrm{Da}$ cutoff membrane and then freeze-dried. LMW EPS was obtained following radical depolymerization, yielding an R-( $40 \%$ sulfate $)$ fraction.

\subsection{Molecular weight determination of LMW exopolysac- charides and unfractionated heparin Sigma}

Each fraction $(2 \mathrm{mg} / \mathrm{ml})$ was analyzed by high-performance size-exclusion chromatography (HPSEC) in $0.1 \mathrm{M}$ ammonium acetate at a flow rate of $0.5 \mathrm{ml} / \mathrm{min}$ using a $25 \times 0.4 \mathrm{~cm}$ i.d. Lichrospher $300 \AA$ Diol $7 \mathrm{UM}$ column (Merck, France) and a $25 \times 0.46 \mathrm{~cm}$ i.d. HEMA SEC BIO 40 10U column (Alltech, France) connected in series. Column calibration was performed with standard pullulans $^{1}$. Area measurements and calculations of $\mathrm{Mw}$ (weight-average molecular mass) and I (polydispersity) were carried out using ARAMIS software (JMBS Développements, Le Fontanil, France).

\subsection{Chemical analyses of $L M W$ exopolysaccharides}

Total neutral sugar content was determined using the orcinol-sulfuric method, with mannose-galactose $(1: 1)$ mixture as standard [31,32]. Uronic acid content was determined according to a previously described procedure [33]. Elemental analysis (C, H, N and S) was performed by the Central Microanalysis Department of the CNRS (Gif/Yvette, France). Sulfate content (sodium salt) was deduced from sulfur analysis according to the following relation: sulfate group $\%=3.22 \times \mathrm{S} \%$. Sulfate content was also determined by Fourier transform infrared analysis. Pellets were obtained by careful grinding of a mixture of $2 \mathrm{mg}$ of EPS with $200 \mathrm{mg}$ of dry $\mathrm{KBr}$. Infrared spectra were recorded on a BOMEM M100 Fourier Transform Infrared Spectrometer with a resolution of $4 \mathrm{~cm}^{-1}$.

\subsection{Clotting assays}

Activated partial thromboplastin time (APTT) with the APTT Organon kit (Organon Technika, France), thrombin clotting time (TT) with purified human thrombin 5 $\mathrm{NIH} \mathrm{U/ml,} \mathrm{reptilase} \mathrm{time,} \mathrm{and} \mathrm{prothrombin} \mathrm{time} \mathrm{were}$ performed as previously described [25]. H-(20\% sulfate), $\mathrm{H}-(40 \%$ sulfate $)$ and $\mathrm{R}-(40 \%$ sulfate $)$ fractions $(0-100 \mu \mathrm{g} /$ $\mathrm{ml})$, unfractionated heparin $(0-3 \mu \mathrm{g} / \mathrm{ml})$ and LMW heparin $(0-6 \mu \mathrm{g} / \mathrm{ml})$ were diluted in human platelet-poor plasma (PPP). These concentrations were chosen to obtain a comparable range of APTT prolongation with all tested products.

\subsection{Thrombin generation test (TGT)}

The fraction with the highest anticoagulant activity and the lowest molecular weight was tested. The R-(40\% sulfate) fraction and unfractionated heparin were diluted in human PPP at various concentrations. Thrombin generation in contact-activated plasma and thromboplastin-activated plasma was measured according to a previously described method [34], with slight modifications [35]. Briefly, thrombin generation was triggered by addition to defibrinated human PPP of a mixture of buffer $\left(\mathrm{CaCl}_{2}\right)$ with cephalin and ellagic acid (APTT-ES, Helena) in the contact-activated system or with thromboplastin (Thromborel-S) in the thromboplastin-activated system. Thrombin generation was stopped at various times by adding a 100 $\mu l$ aliquot of activated PPP to $400 \mu \mathrm{l}$ of $0.01 \mathrm{M}$ EDTA in $0.03 \mathrm{M}$ sodium barbiturate buffer $(\mathrm{pH} 8.35)$ containing

\footnotetext{
1 Pullulans are neutral glucans, whereas oversulfated LMW EPS and heparin are highly negatively charged polysaccharides. Consequently, such calibration does not allow exact measurement of the polysaccharide molecular weight; it was only used for relative comparisons in Tables 1-3. Heparin and LMW EPS (bearing the same negative charge) have very similar molecular weights in our HPSEC system that allows to compare their effect at the same ponderal concentration in Fig. 4.
} 

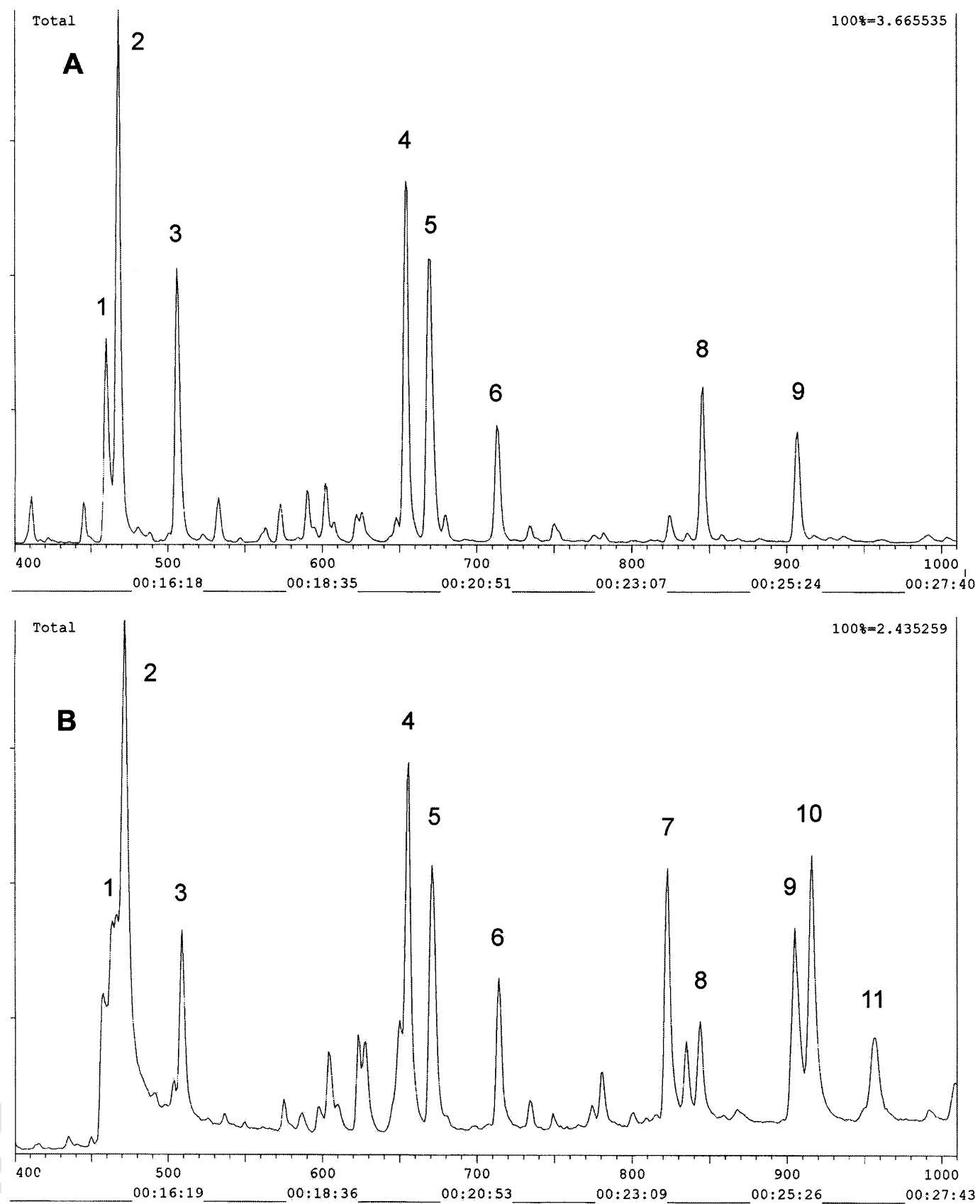

Fig. 1. Separation of methylated alditol acetates derived from A. infernus EPS without reduction (A), and separation of methylated alditol acetates derived from A. infernus EPS with reduction of GalA and GlcA in Gal and Glc respectively (B). OH were methylated by MeI in DMSO using lithium dimethylsulfinyl as anion. Methyl esters of uronic acids were reduced by $\operatorname{LiB}\left(\mathrm{C}_{2} \mathrm{H}_{5}\right)_{3} \mathrm{D}(\mathrm{B})$. The methylated product was then hydrolyzed in $2 \mathrm{M}$ TFA (2 $\mathrm{h}, 120^{\circ} \mathrm{C}$ ), reduced and acetylated before analysis of the mixture by GC/MS.

$0.15 \mathrm{M} \mathrm{NaCl}$ and $0.1 \mathrm{~g} / 1 \mathrm{BSA}$ preincubated at $4^{\circ} \mathrm{C}$. The generated thrombin was quantified by adding $50 \mu \mathrm{l}$ of an EDTA-containing sample to $450 \mu 1$ of $1 \mathrm{mM}$ S-2238. The percentage of inhibition of peak thrombin generation and the lag phase preceding this peak $(\Delta t$ : time interval between the beginning of the test, i.e. the addition of the triggering agent, and the peak value) were calculated for various concentrations of each polysaccharide in plasma (plasma without polysaccharide was used as the control). Results are expressed as the concentration of polysaccha- ride yielding $50 \%$ inhibition $\left(\mathrm{IC}_{50}\right)$ and the $\Delta t$ corresponding to the $\mathrm{IC}_{50}$ value $\left(\Delta t_{\mathrm{IC}_{50}}\right)$. The $\mathrm{IC}_{50}$ value was calculated from the linear relation obtained by plotting the percentage of thrombin inhibition relative to polysaccharide concentration. The $\Delta t_{\mathrm{IC}_{50}}$ value was calculated from the equation obtained by plotting $\Delta t$ as a function of polysaccharide concentration. 

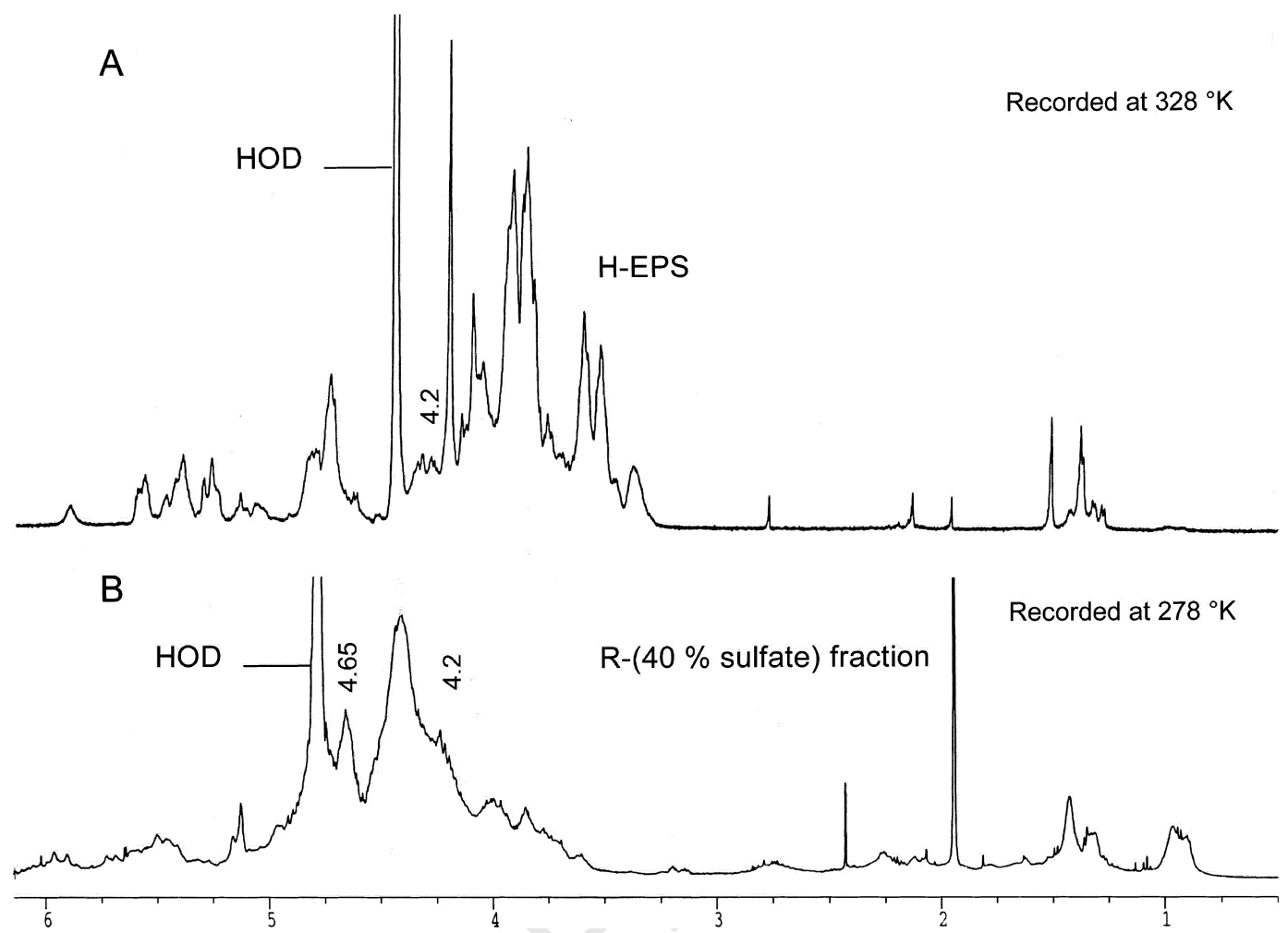

Fig. 2. 1D proton NMR spectra of partially hydrolyzed native EPS (H-EPS) (A) and the R-(40\% sulfate) fraction (B). Spectra were recorded on a Bruker DRX-500 spectrometer, equipped with an indirect $5 \mathrm{~mm}{ }^{1} \mathrm{H}\{\mathrm{BB}\}$ gradient probe head, at a probe temperature of $298 \mathrm{~K}$ or $328 \mathrm{~K}$. Prior to analysis, samples were exchanged twice in $\mathrm{D}_{2} \mathrm{O}$. Chemical shifts are expressed in ppm by reference to an external standard (trimethylsilylpropionic acid). No suppression of the HOD signal was performed.

\subsection{Electrophoretic analysis of serpin binding}

The binding of polysaccharides to human antithrombin (AT) and human heparin cofactor II (HCII) was analyzed by affinity co-electrophoresis according to a previously described technique [36], which allows both protein and polysaccharidic chains to migrate freely during electrophoresis. Briefly, the polysaccharides were electrophoresed in agarose gels through zones containing increasing amounts of AT or HCII. At neutral pH, the electrophoretic mobilities of polysaccharides are much higher than those of serpins, and the binding of polysaccharides to serpins decreases their electrophoretic mobility. As LMW EPS and unfractionated heparin showed very similar molecular weights in our HPSEC assay, they were used at the same ponderal concentration, corresponding to the same molar concentration $(0.7 \mu \mathrm{M})$. Twenty micrograms of polysaccharides were loaded into nine separate transverse slots close to the cathode. Each slot was opposite a rectangular sagittal well in which AT or HCII was cast. AT concentrations in agarose gel were 0 (control), $43 \mu \mathrm{M}$ and $86 \mu \mathrm{M}$, and HCII concentrations were 0 (control), 0.75 $\mu \mathrm{M}$ and $1.5 \mu \mathrm{M}$. The highest concentration of both serpins was obtained after vial reconstitution with $1 \mathrm{ml}$ of distilled water, as recommended by the manufacturer. Electrophoresis was performed at $60 \mathrm{~V}$ and $500 \mathrm{~mA}$ for $3.5 \mathrm{~h}$. Electrophoresis end points were determined by the migration of bromophenol blue, which migrates slower than polysaccharides. After electrophoresis, the gel was soaked in Cetavlon, dried, stained with toluidine blue, bleached and dried again according to a previously described procedure [37].

\section{Results}

\subsection{Composition and methylation studies of native EPS}

GC/MS chromatograms of partially methylated acetates derived from native EPS without reduction showed eight main peaks (Fig. 1A) numbered 1-9 (7 is missing, but appears after reduction, as described below) and identified as 1,3,5-tri- $O$-acetyl-2,4-di- $O$-methyl rhamnitol (1), 1,5-di$O$-acetyl-2,3,4,6-tetra- $O$-methyl glucitol (2), 1,5-di- $O$-acetyl-2,3,4,6-tetra- $O$-methyl galactitol (3), 1,4,5-tri- $O$-acetyl2,3,6-tri- $O$-methyl galactitol (4), 1,4,5-tri- $O$-acetyl-2,3,6tri- $O$-methyl glucitol (5), 1,5,6-tri- $O$-acetyl-2,3,4-tri- $O$ methyl galactitol (6), 1,3,5,6-tetra- $O$-acetyl-2,4-di- $O$-methyl galactitol (8), 1,3,4,5,6-penta- $O$-acetyl-2- $O$-methyl galactitol (9). Peaks 2 and 3 were large (the former about twice the size of the latter), corresponding to terminal glucose and galactose residues respectively. Such high quantities of non-reducing ends indicated that this EPS was highly branched. Peaks 4 and 5 were due to 1,4-linked 


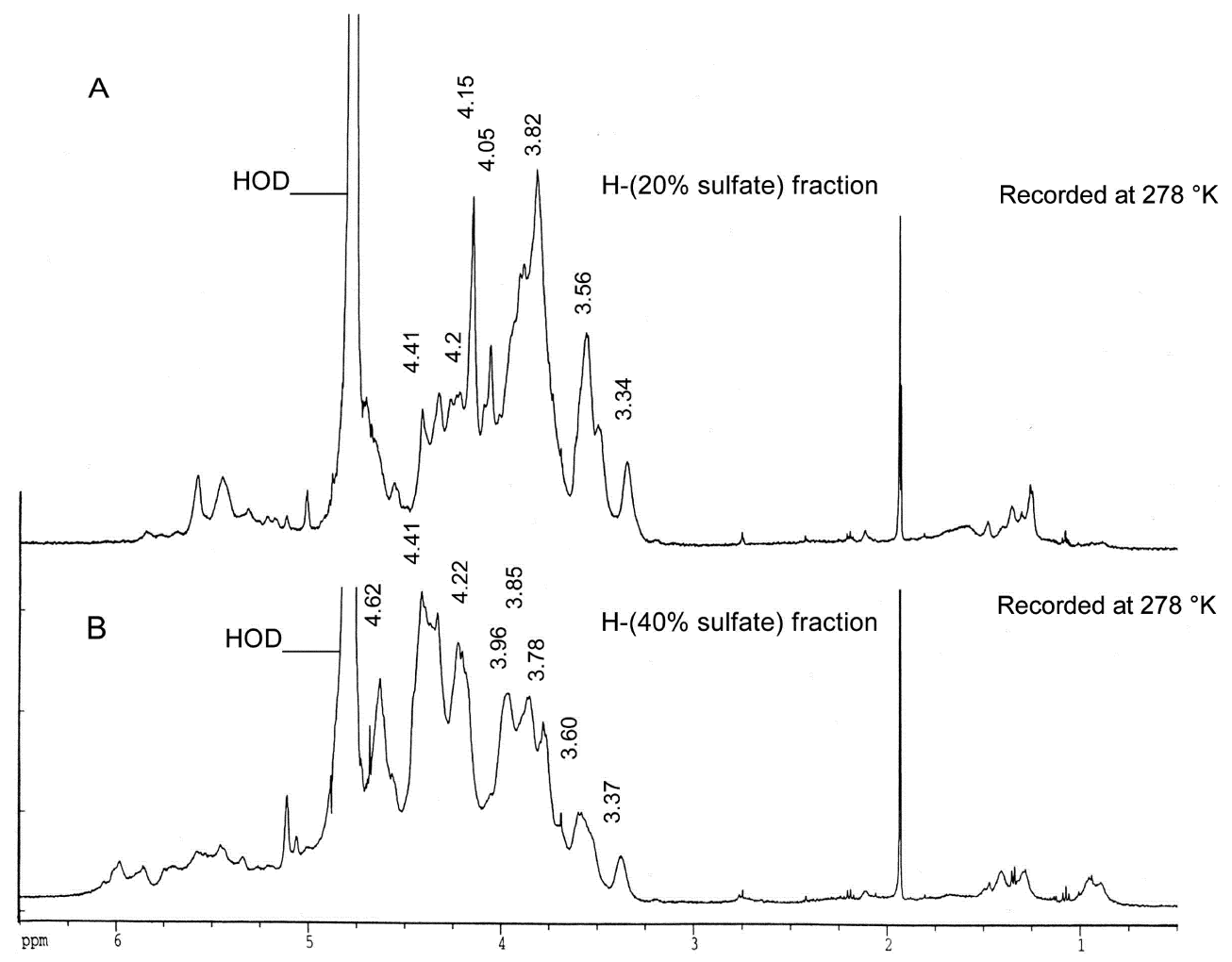

Fig. 3. 1D proton NMR spectra of the H-(20\% sulfate) fraction (A) and the H- $(40 \%$ sulfate $)$ fraction (B). Spectra were recorded on a Bruker DRX-500 spectrometer, equipped with an indirect $5 \mathrm{~mm}{ }^{1} \mathrm{H}\{\mathrm{BB}\}$ gradient probe head, at a probe temperature of $298 \mathrm{~K}$ or $328 \mathrm{~K}$. Prior to analysis, samples were exchanged twice in $\mathrm{D}_{2} \mathrm{O}$. Chemical shifts are expressed in ppm by reference to an external standard (trimethylsilylpropionic acid). No suppression of the HOD signal was performed.

galactose and glucose respectively. The other smaller peaks were attributed to 1,3 -linked rhamnose (peak 1) and variously linked galactose residues (1,6-linked, 1,3,6linked and 1,3,4,6-linked; peaks 6,8 and 9 respectively). After reduction of carboxylic acid functions (Fig. 1B), three additional peaks appeared, but the main sugar residue was still terminal glucose. Peak 7 (1,4,5-tri- $O$-acetyl2,3,6-tri- $O$-methyl glucitol) corresponded to two kinds of glucuronic acid residues (1,2- or 1,4-linked), peak 9 to a mixture of 1,3,4,6-linked galactose and 1,3,4-linked galacturonic acid in equal proportions according to MS data (333/335 ratio was around 1), peak 10 to 1,3,4-linked glucuronic acid, and peak 11 to 1,2,4-linked glucuronic acid. These results indicate that side chains were mainly borne by uronic acids. Methylation analyses performed on polysaccharides from various batches and on $H$-EPS gave similar results, although with some variations in peak intensities, especially for peak 1 which sometimes almost disappeared. Nevertheless, the main peaks were always 2, 3, 4 and 5 without carboxylic acid reduction, and peaks 7, 9 and 10 appeared when reduction was performed. These results indicate that the bacterium secreted two polysaccharides. The major one (the subject of our study) was composed only of glucose, galactose, glucuronic and galacturonic acids, in accordance with the osidic composition previously described [9], whereas the other (a minor compound) contained significant quantities of rhamnose.

Table 1

Molecular mass, chemical composition and yield of the LMW sulfated EPS fractions (fractions were obtained after chemical sulfation, acid hydrolysis or radical depolymerization)

\begin{tabular}{lllllll}
\hline LMW EPS fractions & $\mathrm{Mw}^{\mathrm{a}}\left(\times 10^{3} \mathrm{~g} / \mathrm{mol}\right)$ & $I^{\mathrm{a}}(\mathrm{Mw} / \mathrm{Mn})$ & Neutral sugars $^{\mathrm{b}}(\%)$ & Uronic acids $^{\mathrm{c}}(\%)$ & Sulfate $^{\mathrm{d}}(\%)$ & Yield $^{\mathrm{e}}(\%)$ \\
\hline H-(20\% sulfate $)$ & 25 & 1.4 & 48 & 29 & 19 & 42 \\
H-(40\% sulfate) & 35 & 1.7 & 35 & 19 & 34 & 42 \\
R-(40\% sulfate) & 24 & 1.3 & 31 & 20 & 37 & 75 \\
\hline
\end{tabular}

${ }^{\mathrm{a}} \mathrm{Mw}$ (weight-average molecular mass), Mn (number-average molecular mass), and $I$ (polydispersity) were measured by HPSEC using pullulans as standards.

${ }^{\mathrm{b}}$ Total neutral sugar content was determined by the orcinol-sulfuric method [31,32].

${ }^{\mathrm{c}}$ Uronic acid content was determined according to the procedure described by Blumenkrantz and Asboe-Hansen [33].

${ }^{\mathrm{d}}$ Deduced from sulfur content.

${ }^{\mathrm{e}}$ Based on recovered materials from starting unfractionated hydrolyzed oversulfated EPS. 
Table 2

Anticoagulant activity measured by activated partial thromboplastin time performed with the Organon APTT kit

\begin{tabular}{|c|c|c|c|c|}
\hline \multirow[t]{3}{*}{ LMW EPS fractions or heparins } & \multicolumn{4}{|c|}{ Activated partial thromboplastin time (s) } \\
\hline & \multicolumn{4}{|c|}{$\mu \mathrm{g} / \mathrm{ml} \mathrm{PPP}$} \\
\hline & 0 & 10 & 50 & 100 \\
\hline H-(20\% sulfate $)$ & $39 \pm 2$ & $39.4 \pm 2$ & $49.8 \pm 3$ & 66.2 \\
\hline \multirow[t]{3}{*}{$\mathrm{H}-(40 \%$ sulfate $)$} & $39 \pm 2$ & $78.4 \pm 3$ & $>180$ & $>180$ \\
\hline & \multicolumn{4}{|c|}{$\mu \mathrm{g} / \mathrm{ml}$ PPP } \\
\hline & 0 & 10 & 20 & 30 \\
\hline \multirow[t]{3}{*}{$\mathrm{R}-(40 \%$ sulfate $)$} & $38 \pm 3$ & $85 \pm 2$ & $121 \pm 2$ & $164 \pm 3$ \\
\hline & \multicolumn{4}{|c|}{$\mu \mathrm{g} / \mathrm{ml}$ PPP } \\
\hline & 0 & 2 & 4 & 6 \\
\hline \multirow[t]{3}{*}{ LMW heparin } & $38 \pm 3$ & $57 \pm 1$ & $78 \pm 1$ & $100 \pm 0.5$ \\
\hline & \multicolumn{4}{|c|}{$\mu \mathrm{g} / \mathrm{ml}$ PPP } \\
\hline & 0 & 1.5 & 2 & 3 \\
\hline Unfractionated heparin & $38 \pm 3$ & $85 \pm 2$ & $117 \pm 4$ & $178 \pm 5$ \\
\hline
\end{tabular}

Results are expressed as means \pm S.D. $(n=5)$.

\subsection{Nuclear magnetic resonance spectroscopy}

Due to its high molecular weight, native EPS could not be studied directly by NMR spectroscopy. A partially hydrolyzed compound (H-EPS) was prepared, and its NMR spectrum was recorded as well as the spectra of the three oversulfated LMW EPSs: H-(20\% sulfate), H-(40\% sulfate) and R-(40\% sulfate) fractions (see Section 2). The ${ }^{1} \mathrm{H}-1 \mathrm{D}$ spectrum of $\mathrm{H}$-EPS is shown in Fig. 2A. From the low field, signals in the H-EPS spectrum were gathered in four clusters. The first $(5.5-5.0 \mathrm{ppm})$ corresponded to anomeric protons of $\alpha$-linked osidic units, and the second (4.8-4.4 ppm) to protons of $\beta$-linked anomeric or sulfated positions (see below). The third (4.3-3.3) was attributed to $\mathrm{H} 3, \mathrm{H} 4, \mathrm{H} 5$ and $\mathrm{H} 6$ of various sugar residues, and the fourth (1.4-1.2 ppm) to methyl groups of rhamnose residues. Some impurities (above $1 \mathrm{ppm}$ ) also appeared. The COSY spectrum (not shown) displayed a cross-peak corresponding to a sulfated 2- $O$-position $(\mathrm{H} 2$ at $4.75 \mathrm{ppm})$ of an $\alpha$-linked residue ( $\mathrm{H} 1$ at $5.28 \mathrm{ppm})$, which was necessa- rily a glucuronic acid as methylation analysis indicated that only glucuronic acids were $2-O$-substituted. After sulfation (Figs. 2B and 3A,B), there were many more resonances between 4.2 and $4.8 \mathrm{ppm}$ (protons of sulfated positions) than with H-EPS (Fig. 2A), especially for the more sulfated fractions: R-(40\% sulfate) and $\mathrm{H}-(40 \%$ sulfate). For the R-(40\% sulfate) fraction, there was no resonance between 3.5 and $3.0 \mathrm{ppm}$ (corresponding to the area of $\mathrm{H} 2$ and $\mathrm{H} 3$ of $\beta$-linked residues). However, $\mathrm{H}-(40 \%$ sulfate $)$ and $\mathrm{H}-(20 \%$ sulfate $)$ maintained signals at $3.5-3.6 \mathrm{ppm}$ ( $\mathrm{H} 2$ of $\beta$-linked galactose) and $3.3-3.4 \mathrm{ppm}(\mathrm{H} 2$ of $\beta$ linked glucose), probably because more labile sulfates were partially eliminated during acid hydrolysis, especially 2-O-sulfate that is much more susceptible to acid-catalyzed ester hydrolysis [38]. On the other hand, the resonances at $4.2 \mathrm{ppm}$ ( $\mathrm{H} 6$ of $\mathrm{CH}_{2} \mathrm{OSO}_{3}^{-}$) [39] were low in sample $\mathrm{H}$ (20\% sulfate), intermediate in R-(40\% sulfate) and high in $\mathrm{H}-(40 \%$ sulfate), which showed the greatest sulfation at the 6-position. It is noteworthy that $\mathrm{H}-(20 \%$ sulfate), which exhibited few additional resonances between 4.2

Table 3

Anticoagulant activity measured by thrombin time performed with purified human thrombin $(5 \mathrm{NIH} \mathrm{U} / \mathrm{ml})$

\begin{tabular}{|c|c|c|c|c|c|}
\hline \multirow[t]{3}{*}{ LMW EPS fractions or heparins } & \multicolumn{5}{|c|}{ Thrombin time (s) } \\
\hline & \multicolumn{5}{|c|}{$\mu \mathrm{g} / \mathrm{ml} \mathrm{PPP}$} \\
\hline & 0 & 10 & 15 & 20 & 30 \\
\hline \multirow[t]{3}{*}{ R-(40\% sulfate) } & $18 \pm 1.7$ & $26 \pm 2.0$ & $37 \pm 1.7$ & $55 \pm 3.7$ & $>200$ \\
\hline & \multicolumn{5}{|c|}{$\mu \mathrm{g} / \mathrm{ml}$ PPP } \\
\hline & 0 & 1.5 & 2 & 4 & 6 \\
\hline \multirow[t]{3}{*}{ LMW heparin } & $18 \pm 1.7$ & $53 \pm 6$ & $96 \pm 8$ & $>200$ & $>200$ \\
\hline & \multicolumn{5}{|c|}{$\mu \mathrm{g} / \mathrm{ml} \mathrm{PPP}$} \\
\hline & 0 & 0.75 & 1.5 & 2 & 3 \\
\hline Unfractionated heparin & $18 \pm 1.7$ & $53 \pm 7$ & $>200$ & $>200$ & $>200$ \\
\hline
\end{tabular}

Results are expressed as means \pm S.D. $(n=5)$. 
Table 4

Polysaccharide concentrations producing $50 \%$ inhibition $\left(\mathrm{IC}_{50}\right)$ of peak thrombin generation, and the time lag corresponding to these $\mathrm{IC}_{50}\left(\Delta t_{\mathrm{IC}}\right)$

\begin{tabular}{|c|c|c|c|c|}
\hline & \multicolumn{2}{|c|}{ Contact-activated system } & \multicolumn{2}{|c|}{ Thromboplastin-activated system } \\
\hline & $\mathrm{IC}_{50}\left(\mu \mathrm{g} \mathrm{ml}^{-1}\right)$ & $\begin{array}{l}\Delta t_{\mathrm{IC}_{50}}(\min ) \\
\Delta t(\min )^{\mathrm{a}}\end{array}$ & $\mathrm{IC}_{50}\left(\mu \mathrm{g} \mathrm{ml}^{-1}\right)$ & $\begin{array}{l}\Delta t_{\mathrm{IC}_{50}}(\min ) \\
\Delta t(\min )^{\mathrm{a}}\end{array}$ \\
\hline Control $^{\mathrm{a}}$ & & $0.85 \pm 0.13$ & & $1.00 \pm 0.00$ \\
\hline R-( $40 \%$ sulfate $)$ & $58 \pm 17$ & $4.8 \pm 1.0$ & $53 \pm 6$ & $1.00 \pm 0.00$ \\
\hline Heparin & $0.65 \pm 0.08$ & $1.06 \pm 0.23$ & $0.48 \pm 0.07$ & $1.00 \pm 0.00$ \\
\hline
\end{tabular}

Results are expressed as means \pm S.D. $(n=5)$.

${ }^{\mathrm{a}} \Delta t$ is the lag phase observed in the absence of polysaccharide (control).

and $4.7 \mathrm{ppm}$ ( $\mathrm{H}$ of sulfated positions), lacked the peak at 4.65-4.62 present in both $\mathrm{R}-(40 \%$ sulfate $)$ and $\mathrm{H}-(40 \%$ sulfate) fractions (attributed to $\mathrm{H} 4$ of a $4-O$-sulfated position [39] or to $\mathrm{H} 2$ and/or $\mathrm{H} 3$ of 2,3- $O$-disulfated residues $[28,40])$. The COSY spectrum was too complex to allow any clear distinction to be made.

\subsection{Molecular weight and composition of LMW exopoly- saccharides}

Two oversulfated high-molecular-weight EPSs isolated after chemical sulfation showed sulfate contents of $20 \%$ and $40 \%$ respectively, as determined by Fourier transform infrared analysis and elemental analysis (data not shown). These two oversulfated EPSs were partially depolymerized by acid hydrolysis in an attempt to isolate LMW EPSs. After fractionation by gel filtration chromatography, two LMW fractions were isolated from each hydrolyzed EPS: the $\mathrm{H}-(20 \%$ sulfate $)$ and $\mathrm{H}-(40 \%$ sulfate $)$ fractions respectively. The fractions were homogeneous in size, with a polydispersity $(I)$ below 2, and were produced with a good yield (Table 1). Depolymerization did not alter the osidic composition of the H-LMW EPS fractions, and a slight decrease $(15 \%)$ of sulfate content was observed only with the oversulfated EPS initially containing 40\% sulfate groups. The H-LMW EPS fractions had the same sulfate/ total sugar ratios as the oversulfated high molecular weight EPS. The oversulfated EPS with the highest sulfate content $(40 \%)$ was also depolymerized by a radical process, resulting in the isolation of an LMW EPS fraction, $\mathrm{R}-(40 \%$ sulfate $)$ fraction, which was homogeneous, with polydispersity $(I)$ below 1.5 , and produced with a good yield (Table 1).

\subsection{Anticoagulant properties of modified exopolysaccha- rides}

The in vitro anticoagulant activities of modified EPSs were measured in APTT and then compared with those of heparins. Among the H-LMW EPSs, only the H-(40\% sulfate) fraction was able to prolong APTT appreciably. The same anticoagulant effect was obtained for the $\mathrm{H}-(40 \%$ sulfate) fraction, LMW heparin and unfractionated heparin at 10, 4 and $1.5 \mu \mathrm{g} / \mathrm{ml}$ respectively. The R-(40\% sulfate) fraction was as potent as the $\mathrm{H}-(40 \%$ sulfate $)$ fraction in prolonging APTT $(10 \mu \mathrm{g} / \mathrm{ml}$ were required to obtain the doubling of APTT; Table 2). The anticoagulant effect of R-(40\% sulfate) was also evaluated by $\mathrm{TT}$ and compared with that of heparins. An equivalent prolongation was observed for this fraction, LMW heparin and unfractionated heparin at $20,1.5$ and $0.75 \mu \mathrm{g} / \mathrm{ml}$ respectively (Table 3). The R-(40\% sulfate) fraction had no significant effect on reptilase time and prothrombin time (data not shown) at the tested concentrations $(10-50 \mu \mathrm{g} / \mathrm{ml})$.

The effect of the R-(40\% sulfate) fraction on thrombin generation was evaluated in the contact-activated and thromboplastin-activated systems and compared with that of unfractionated heparin (Table 4). Like heparin, the R-(40\% sulfate) fraction inhibited thrombin generation after activation of intrinsic and extrinsic pathways. In the contact-activated system, the $\mathrm{IC}_{50}$ was $58 \pm 17 \mu \mathrm{g} / \mathrm{ml}$ with $\mathrm{R}-(40 \%$ sulfate $)$ as compared to $0.65 \pm 0.08 \mu \mathrm{g} / \mathrm{ml}$ with unfractionated heparin. R-(40\% sulfate) caused a greater delay in contact-induced thrombin generation than did heparin, with the lag phase increasing in proportion to its concentration. The $\Delta t_{\mathrm{IC}_{50}}$ value was $4.8 \pm 1.0 \mathrm{~min}$ compared to $1.06 \pm 0.23 \mathrm{~min}$ with unfractionated heparin. In the thromboplastin-activated system, the $\mathrm{IC}_{50}$ was $53 \pm 6$ $\mu \mathrm{g} / \mathrm{ml}$ with R-(40\% sulfate) compared to $0.48 \pm 0.07 \mu \mathrm{g} / \mathrm{ml}$ with unfractionated heparin. In contrast to contact-induced thrombin generation, the R-(40\% sulfate) fraction, like heparin, was not effective in delaying thrombin formation in the thromboplastin-activated system.

The interaction of the R-(40\% sulfate) fraction with serpins was analyzed by ACE. In the presence of antithrombin (Fig. 4A), the patterns differed for R-(40\% sulfate), unfractionated heparin and dextran sulfate (all loaded at the same concentration of $20 \mu \mathrm{g})$. R-(40\% sulfate) mobility was reduced, giving a single spot at the highest protein concentration, whereas antithrombin split the migrating heparin front into two distinct fronts, as previously shown [36]. With dextran sulfate, a part of the migration front was delayed at the highest protein concentration. In experiments performed with lower antithrombin concentrations, a delay was also observed, although the differences were not so well clear-cut (data not shown). In the presence of heparin cofactor II (Fig. $4 \mathrm{~B})$, a fractionation of $\mathrm{R}-(40 \%$ sulfate $)$ migration front was observed for both protein concentrations tested, which suggests that a subpopulation bound strongly to 

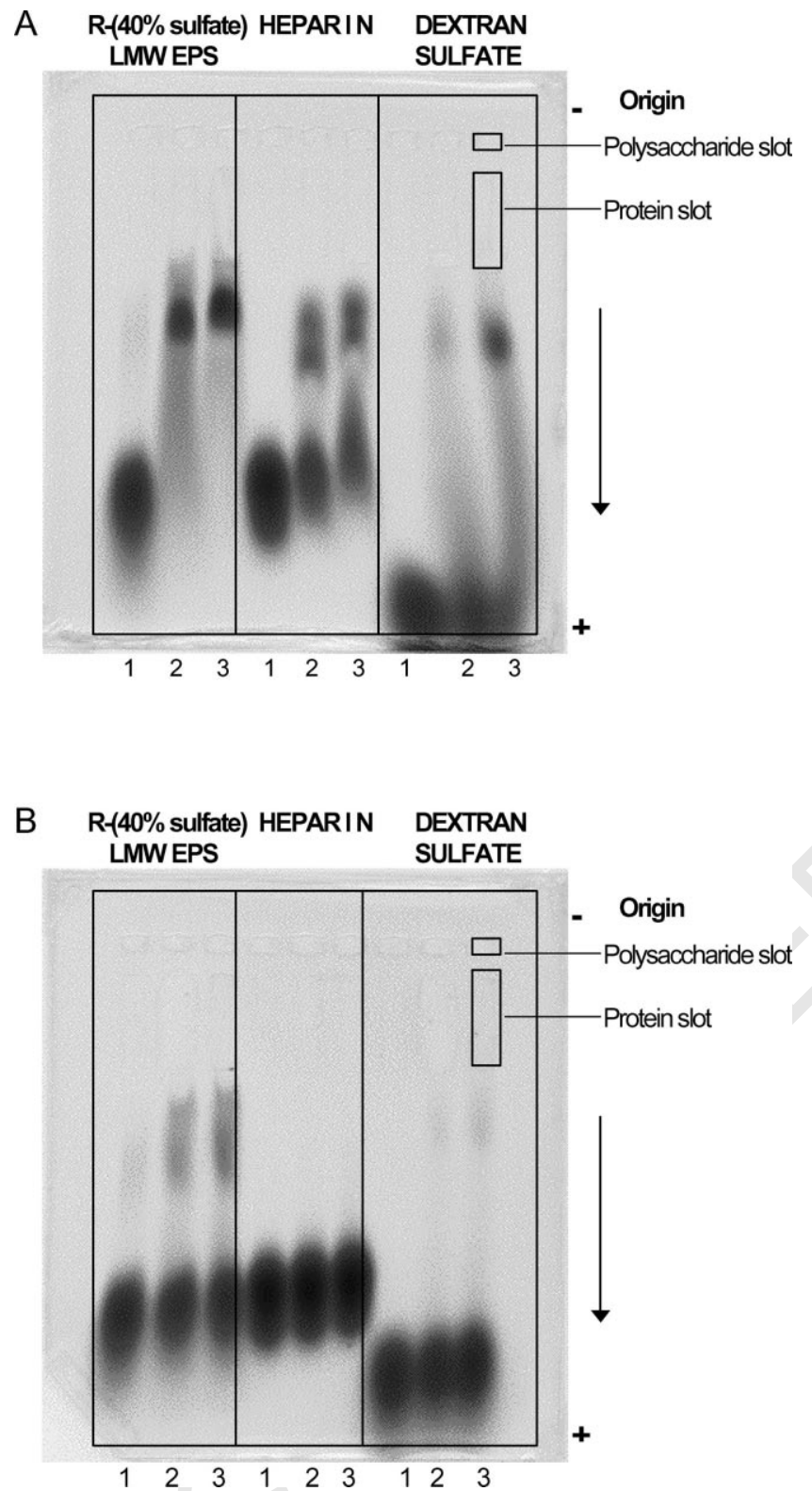

Fig. 4. Analysis of R-( $40 \%$ sulfate)-antithrombin binding (A) and R( $40 \%$ sulfate)-heparin cofactor II binding (B). Electrophoresis of polysaccharides $(20 \mu \mathrm{g})$ through zones containing buffer (control) or protein. Concentrations of antithrombin (A) were 0 (1), 43 (2) and $86 \mu \mathrm{M}$ (3), and concentrations of heparin cofactor II (B) were 0 (1), 0.75 (2) and $1.5 \mu \mathrm{M}(3)$.

heparin cofactor II. With unfractionated heparin and dextran sulfate, the migration front was similar to that of the control (buffer).

\section{Discussion}

Studies have been performed on naturally occurring or synthetic sulfated polysaccharides with similar biological activities to those of heparin (referred to as heparinoids) $[1,41]$. The present study provided structural data on a new polysaccharide and evaluated its anticoagulant properties after chemical modifications.

The A. infernus EPS appears to have an original backbone structure made up primarily of glucose, galactose and uronic acid residues bound by $1 \rightarrow 3$ or/and $1 \rightarrow 4$ linkages, in the manner of most other anticoagulant polysaccharides. The presence of side chains in such an active compound is a quite uncommon feature and has been reported only for a fucosylated chondroitin sulfate isolated from an echinoderm [42] and in algal fucans [28]. It was determined that the anticoagulant properties of fucosylated chondroitin sulfate were related to sulfated fucose branches. Interestingly, the side chain feature allows the preparation of new compounds that would be difficult to obtain by a synthetic approach.

Considering its low sulfate content, it is not surprising that native EPS is a non-anticoagulant product. To prepare a new active product (i.e. with anticoagulant activity), it was necessary to modify the EPS in order to control critical features such as chain length and the degree of sulfation. Chemical sulfation, though a non-specific method, makes it possible to obtain a number of compounds variously sulfated at originally free positions (especially in unsubstituted galactose and glucose branches). Accordingly, LMW fractions with a molecular weight range of $20-30 \times 10^{3} \mathrm{~g} / \mathrm{mol}$ and different sulfate contents were isolated in this study. Anticoagulant activity increased with sulfate ester content, indicating that sulfate esters play a major role in the biological activity. Free radical depolymerization did not lead to significant desulfation in our experimental conditions, as previously noted by Volpi et al. for chondroitin sulfate [37]. Nuclear magnetic resonance data showed that LMW EPS was less sulfated in the 6-O-position after free radical depolymerization ( $\mathrm{R}$ (40\% sulfate)) than after depolymerization by acid hydrolysis (H-(40\% sulfate)); however, the anticoagulant activities were similar. In fact, most of these sulfate groups are not essential to the presence of anticoagulant properties. Many anticoagulant sulfated polysaccharides are free of sulfate groups in the 6-position (e.g. fucan, pentosan sulfate, dermatan sulfate, etc.). It has recently been reported that dermatan sulfate with 4-O-sulfated galactosamine showed a strong affinity for HCII while dermatan sulfate sulfated in the 6-position had no anticoagulant activity at all despite its high sulfate content [43]. The free radical depolymerized product also had residues sulfated in the 4- $O$-position and disulfated in the 2,3-positions, as is often the case for anticoagulant sulfated polysaccharides.

Our experiments showed that anticoagulant activity was higher with $40 \%$ than $20 \%$ of sulfate esters. The LMW EPS depolymerized by the free radical process $(40 \%$ sulfate content, $24 \times 10^{3} \mathrm{~g} / \mathrm{mol}$ ) was less efficient than LMW heparin and unfractionated heparin in clotting assays $(2.5$ and 6.5 times respectively in APTT), but more efficient than LMW dermatan sulfate [44] or LMW fucoidan $[25,45]$ and just as efficient as sodium and calcium pento- 
san polysulfate [13]. This R-(40\% sulfate) LMW EPS inhibited thrombin generation after stimulation by both contact-activated and thromboplastin-activated systems $(50 \%$ inhibition in both systems with the same concentration). The R- $(40 \%$ sulfate) fraction only delayed contact-induced thrombin generation, as observed with heparin and fucoidan [35], providing a much longer lag phase with the $\mathrm{R}$ ( $40 \%$ sulfate) fraction $\left(\Delta t_{\mathrm{IC}_{50}}=4.8 \mathrm{~min}\right)$ than with heparin and fucoidan ( 1 and $3 \mathrm{~min}$ respectively). Affinity co-electrophoresis experiments performed in the presence of antithrombin or heparin cofactor II showed that R- $(40 \%$ sulfate) chains strongly bound both serpins (the total population for antithrombin and only a subpopulation for heparin cofactor II). These results suggest that the $\mathrm{R}-(40 \%$ sulfate) fraction inhibits thrombin activity or thrombin formation in three ways, as proposed by Ofosu et al. for heparin [46]: (1) by catalysis of thrombin inhibition by antithrombin; (2) by catalysis of thrombin inhibition by heparin cofactor II; and (3) by inhibition of the prothrombinase complex or the expression of its activity. However, the differences in affinity observed for both serpins between R-( $40 \%$ sulfate) and heparin could account for the differences in the lag phase of the contact-induced thrombin generation system. Several recent studies have shown that the catalytic effect on thrombin inhibition (rather than factor Xa inhibition) is critical for the expression of anticoagulant and optimal antithrombotic effects [46]. Moreover, polysaccharides with lower anticoagulant activity than heparin could exhibit a potent antithrombotic effect with less hemorrhagic risk. The backbone structure determines the substitution pattern endowing the sulfated polysaccharide with a specific mechanism. In the case of fucans, comparison of the anticoagulant activity of algal fucans with that of regular and linear sulfated fucans from marine echinoderms suggests that the high activity is correlated with the presence of sulfated fucose branches [14]. On the other hand, the presence of 2,3-disulfated residues is also an important requirement for such activity [28]. Indeed different structural features determine not only the anticoagulant potency of sulfated polysaccharides, but also the mechanism by which they exert this activity [15].

In summary, an active (anticoagulant) product was prepared from a new exopolysaccharide after sulfation and controlled free radical depolymerization. Original sulfation patterns were obtained due to the unique backbone structure consisting of many different monosaccharide building units, glycosidic linkage types and unit branches. Polysaccharides of this type can be used to constitute a library of compounds useful for elucidation of the structure-activity relationship. Moreover, microbial polysaccharides, unlike those found in plants or animals, can be produced in controlled conditions and are thus not subject to variations in quality and to the potential risk of viral contamination, as with animal products. Microorganisms can be considered a renewable source of a large variety of important metab- olites, including exopolysaccharides [5]. The novel exopolysaccharide investigated here could provide a biochemical entity with suitable functions for obtaining a drug with a good benefit/risk ratio. Further studies are needed to improve our understanding of the EPS anticoagulant mechanism in vitro and the critical structural features required for elaboration of this activity. It will also be necessary to check the anticoagulant and antithrombotic effects of this new exopolysaccharide in vivo in animal models.

\section{Acknowledgements}

The authors are grateful to Claude Sternberg for technical assistance and to Dr. Jean Guezennec for helpful criticism and contributions. This work was supported by IFREMER/CNRS (URM2: Unité de Recherche Marine No. 2), Université Paris 13, INSERM U 428 and Université Paris V.

\section{References}

[1] G. Franz, S. Alban, Int. J. Biol. Macromol. 17 (1995) 311-314.

[2] J. Guezennec, P. Pignet, G. Raguenes, E. Deslandes, Y. Lijour, E. Gentric, Carbohydr. Polym. 24 (1994) 287-294.

[3] H. Rougeaux, R. Pichon, N. Kervarec, G.H.C. Raguenes, J.G. Guezennec, Carbohydr. Polym. 31 (1996) 237-242.

[4] H. Sudo, J.G. Burgess, H. Takemasa, N. Nakamura, T. Matsunaga, Curr. Microbiol. 30 (1995) 219-222.

[5] I.W. Sutherland, in: H.J. Rehm, G. Reed (Eds.), Biotechnology, Vol. 6, VCH, Weinheim, 1996, pp. 613-657.

[6] P. Vincent, P. Pignet, F. Talmont, L. Bozzi, B. Fournet, J. Guezennec, Appl. Environ. Microbiol. 60 (1994) 41344141.

[7] H. Rougeaux, P. Talaga, R.W. Carlson, J. Guezennec, Carbohydr. Res. 312 (1998) 53-59.

[8] H. Rougeaux, N. Kervarec, R. Pichon, J. Guezennec, Carbohydr. Res. 322 (1999) 40-45.

[9] G.H. Raguenes, A. Peres, R. Ruimy, P. Pignet, R. Christen, M. Loaec, H. Rougeaux, G. Barbier, J.G. Guezennec, J. Appl. Microbiol. 82 (1997) 422-430.

[10] J. Guezennec, P. Pignet, Y. Lijour, E. Gentric, J. Ratiskol, S. ColliecJouault, Carbohydr. Polym. 37 (1998) 19-24.

[11] W. Worawattanamateekul, K. Okutani, Nippon Suisan Gakk. 58 (1992) 1729-1733.

[12] M. Matsuda, S. Shigeta, K. Okutani, Mar. Biotechnol. 1 (1999) 6873.

[13] J. Giedrojc, P. Radziwon, M. Klimiuk, M. Bielawiec, H.K. Breddin, J. Kloczko, J. Physiol. Pharmacol. 50 (1999) 111-119.

[14] P.A.S. Mourao, M.A.M. Guimaraes, B. Mulloy, S. Thomas, E. Gray Brit, J. Haematol. 101 (1998) 647-652.

[15] J.D. San Antonio, J. Slover, J. Lawler, M.J. Karnovsky, A.D. Lander, Biochemistry 32 (1993) 4746-4755.

[16] J. Weitz, J. Hirsh, J. Lab. Clin. Med. 122 (1993) 364-373.

[17] U. Lindahl, Haemostasis 29 (1999) 38-47.

[18] G.E. Raskob, Curr. Opin. Hematol. 2 (1995) 372-379.

[19] J. Hirsh, J.I. Weitz, Lancet 353 (1999) 1431-1436.

[20] K. Andrassy, V. Eschenfelder, Thromb. Res. 81 (1996) S29-S38.

[21] M. Verstraete, P. Zoldhelyi, Drugs 6 (1995) 856-884.

[22] R.J. Linhardt, R.E. Hileman, Gen. Pharmacol. 26 (1995) 443-451.

[23] G. Mascellani, L. Liverani, B. Parma, G.L. Bergonzini, P. Bianchini, Thromb. Res. 84 (1996) 21-32. 
[24] R.M. Maarouf, M. Jozefowicz, J. Tapon Bretaudiere, J. Jozefonvicz, A.M. Fischer, Biomaterials 18 (1997) 359-366.

[25] S. Mauray, C. Sternberg, J. Theveniaux, J. Millet, C. Sinquin, J. Tapon Bretaudiere, A.M. Fischer, Thromb. Haemost. 74 (1995) $1280-1285$.

[26] S. Hakomori, J. Biochem. 55 (1964) 205-208.

[27] W.S. York, A.G. Darvill, M. McNeil, T.T. Stevenson, P. Albersheim, Methods Enzymol. 118 (1985) 3-40.

[28] L. Chevolot, A. Foucault, F. Chaubet, N. Kervarec, C. Sinquin, A.M. Fisher, C. Boisson-Vidal, Carbohydr. Res. 319 (1999) 154-165.

[29] T. Nishino, T. Nagumo, Carbohydr. Res. 229 (1992) 355-362.

[30] A. Nardella, F. Chaubet, C. Boisson Vidal, C. Blondin, P. Durand, J. Jozefonvicz, Carbohydr. Res. 289 (1996) 201-208.

[31] C. Rimington, Biochem. J. 25 (1931) 1062-1071.

[32] J. Tilmans, K. Philippi, Biochemistry Z 215 (1929) 36-60.

[33] N. Blumenkrantz, G. Asboe-Hansen, Anal. Biochem. 54 (1973) 484 489.

[34] F.A. Ofosu, G.J. Modi, L.M. Smith, A.L. Cerskus, J. Hirsh, M.A. Blajchman, Blood 64 (1984) 742-747.

[35] S. Mauray, E. De Raucourt, F. Chaubet, O. Maiga-Revel, C. Sternberg, A.M. Fischer, J. Biomater. Sci. Polym. Ed. 9 (1998) 373-387.

[36] M.K. Lee, A.D. Lander, Proc. Natl. Acad. Sci. USA 88 (1991) 2768 2772.
[37] N. Volpi, I. Sandri, T. Venturelli, Carbohydr. Res. 279 (1995) $193-$ 200.

[38] R. Falshaw, R.H. Furneaux, G.C. Slim, in: P. Finch (Ed.), Carbohydrates. Structures, Syntheses and Dynamics, Kluwer Academic Publishers, Dordrecht, 1999, pp. 107-149.

[39] R.R. Contreras, J.P. Kamerling, J. Breg, F.G. Vliegenhart, Carbohydr. Res. 179 (1988) 411-418.

[40] E.A. Yates, F. Santini, A. Bisio, C. Cosentino, Carbohydr. Res. 298 (1997) 335-340.

[41] N. Harada, M. Maeda, Biosci. Biotechnol. Biochem. 62 (1998) 16471652.

[42] P.A.S. Mourao, M.S. Pereira, M.S.G. Pavao, B. Mulloy, D.M. Tollefsen, M.C. Mowinckel, U. Abilgaard, J. Biol. Chem. 271 (1996) 23973-23984.

[43] B. Mulloy, P.A. Mourao, E. Gray, J. Biotechnol. 77 (2000) 123-135.

[44] R.J. Linhardt, U.R. Desai, J. Liu, A. Pervin, D. Hoppensteadt, J. Fareed Biochem. Pharmacol. 47 (1994) 1241-1252.

[45] S. Colliec, C. Boisson-Vidal, J. Jozefonvicz, Phytochemistry 35 (1994) 697-700.

[46] F.A. Ofosu, G.J. Modi, J. Hirsh, M.R. Buchanan, M.A. Blajchman, Ann. NY Acad. Sci. 485 (1986) 41-55. 